\title{
Prevalence of intestinal parasitic infections among urban dwellers in southwest Ethiopia
}

\author{
Amare Mengistu ${ }^{1}$, Solomon Gebre-Selassie ${ }^{2}$, Tesfaye Kassa ${ }^{3}$
}

\begin{abstract}
Background: Intestinal parasitic infections cause serious public health problem in Ethiopia. They are more prevalent in the poor segments of the population with low household income, poor handling of personal and environmental sanitation, overcrowding and limited access to clean water.

Objective: The purpose of this study was to assess the magnitude and pattern of intestinal parasitism in urban communities of southwest Ethiopia.

Methods: This community-based, cross-sectional study was undertaken in Jimma town from October 2004-January 2005. Study subjects were selected using systematic sampling method. Data were gathered through house to house survey using standardized questionnaire. Stool specimens were examined microscopically for the presence of parasite eggs, cysts and trophozoites using direct saline thin smear and formol-ether concentration methods.

Results: Of the total, 754 (83\%) had one or more intestinal parasitic infections. T. trichiura, A. lumbricoides and S. mansoni were detected in single infection in 124 (16.4\%), 44 (5.8\%) and 11 (1.5\%) of the infected study subjects, respectively. Polyparasitism was found in 515 (56.7\%) of the total examined. Up to 5 parasites were detected in some individuals. T. trichiura with A. lumbricoides, hookworm and S. mansoni constituted 102 (13.5\%), 33 (4.3\%) and $17(2.2 \%)$ of the double infections, respectively. $H$. nana and $S$. mansoni predominantly affected males than females $(\mathrm{P}<0.05)$. The prevalence of Giardia trophozites and $H$. nana were significantly higher in pre-school children than other age groups $(\mathrm{P}<0.05)$. Higher proportions of teenagers were infected by $A$. lumbricoides and $S$. mansoni. Taeniasis was also dominant in teenagers.

Conclusion: Intestinal parasitosis is highly prevalent in the study area. Public education on how to handle personal hygiene and proper use of latrines should be given to reduce the prevalence of infection. [Ethiop.J.Health Dev.
\end{abstract} 2007;21(1):12-17]

\begin{abstract}
Introduction
Intestinal parasites and protozoan infections are amongst the most common infections worldwide. It is estimated that some 3.5 billion people are affected, and that 450 million are ill as a result of these infections, the majority being children (1). These infections are documented as serious public health problems as they cause iron deficiency anemia, growth retardation in children and other physical and mental health problems (2).
\end{abstract}

Intestinal parasitic infections are more prevalent among the poor sections of population. They are closely associated with low household income, poor personal and environmental sanitation, and overcrowding, limited access to clean water, tropical climate and low altitude. Intestinal parasitic infections are the top global health problems whereas amoebiasis, ascariasis, hookworm infection and trichiuriasis are among the ten most common infections (3). WHO reported that more than 980 million people are infected by A. lumbricoides (4), which is one of the most common public health problem in Africa. Invasive amoebiasis is a major health and social problem in western and southern Africa (3).

Intestinal parasitism has been widespread in Ethiopia. Parasitic helminthic infections are the second most predominant causes of outpatient morbidity in the country. Several studies indicated that the prevalence of parasitic infections were high in the lower altitudes including southwestern Ethiopia (5). Ethiopia has one of the lowest quality drinking water supply and latrine coverage in the world. As comparison by 2000, Ethiopia had only $12 \%$ latrine coverage while Kenya had $87 \%$ (6). The effect of altitude, urbanization, irrigation, and resettlement on the distribution of intestinal parasitism was depicted in previous studies (5, 7-12). Many reports illustrated that $A$. lumbricoides is the most prevalent intestinal parasite in different communities usually occurring together with trichuris infections (13-15). Hookworm infection, strongyloidiasis and enterobiasis are also public health problem though the magnitude is lesser compared to ascariasis. The prevalence of teaniasis alone ranges from $1-48 \%$ and the infection rate with Hymenolopis nana is $3-61 \%(10,12,14,15)$. Schistosomiasis is common in northern region as compared to south and south west regions of Ethiopia (16). Amoebiasis and giardiasis are common causes of intestinal protozoal infections throughout the nation. The prevalence of amoebiasis ranges from $0-4 \%$ and that of giardiasis is $3-23 \%(5,10,14)$.

\footnotetext{
${ }^{1}$ Department of Pharmacology, Faculty of Medical Sciences, Jimma University, P.O. Box 378, Jimma, Ethiopia; ${ }^{2}$ Department of Microbiology, Immunology \& Parasitology, Faculty of Medicine, Addis Ababa University, P.O. Box 21656/1000, Addis Ababa, Ethiopia; ${ }^{3}$ Department of Microbiology, Immunology \& Parasitology, Faculty of Medical Sciences, Jimma University, P.O. Box 378, Jimma, Ethiopia
} 
Previous studies gave due attention to the distributions of intestinal parasites in different altitudes, community groups such as school children or other groups confined to camps $(5,8,10,15,16)$ and communities $(8-11,15)$. Hence, the pattern of intestinal parasitism in a community with diverse groups of people as a whole was not illustrated particularly in the study area. The purpose of this study was to assess the magnitude and patterns of intestinal parasitism in Jimma town, Southwestern Ethiopia.

\section{Methods}

Cross-sectional study was designed from October 2004 January 2005 to determine the magnitude and patterns of intestinal parasitism in Jimma town, southwestern Ethiopia.

Jimma has mean altitude of 1780 meters above sea level. It is the largest town in southern Ethiopia characterized by tropical climate of heavy rainfall and warm climate having a mean annual temperature of $24.9^{\circ} \mathrm{C}$ (17). During the study period, the population was estimated to be 110,000 (17). According to the report of Ministry of Planning and Economic Development, the average household size was 5.2 and the mean monthly income per household was 271 Birr (about 30 USD) [18]. Seventy five percent of the population had access to piped potable water while the remaining $25 \%$ used wells, springs and other sources (19).

All residents of the town were included as the sources of sample population for the study. The study population included residents of Jimma town of all ages and both sexes. Infants with ages less than four months, new settlers less than 2 weeks duration, individuals who were on anti-parasitic drugs at the time of the study or 2 weeks prior to the study were excluded. Multistage sampling technique was employed for the purpose of sampling. The town was divided into three administrative districts (woreda) and further into 13 administrative units (Kebeles).

Sample size was determined using a general formula considering the level of significances at 5\% and assuming the prevalence of intestinal parasitosis to be $80 \%$ (9). In line with it, 239 households for the sample were calculated and of which a total of 908 unit of analysis were selected. Accordingly, 258, 283 and 367 study subjects from Woreda 1, 2 and 3 were taken respectively. Two Kebeles from each Woreda were also selected.

Three well trained persons collected the data through house to house survey to obtain information regarding age, sex, residence, family size, and occupation based on a pre-designed questionnaire. Accordingly, the first household was randomly selected in each Kebele and then the remaining households were selected using systematic sampling method. Besides, stool specimens were collected from all study subjects in tight lead plastic containers. The specimens were examined microscopically for the presence of eggs, trophozoites and cysts. All stool specimens were examined by direct saline thin smear and formal-ether concentration methods and the findings were recorded using pre-prepared formats. Direct saline thin smear was chosen because of its cheapness, simple, and reliable qualities. Data collection and microscopic examinations were supervised regularly. In addition, the time required for the procedure was relatively short requiring no sophisticated equipments.

Direct thin wet smear in normal saline and Lugol's iodine solution was done immediately at convenient places for the presence of trophozoites and cysts. In addition, stool specimens were transported to laboratory section using $8 \%$ formalin. Formol-ether concentration method was carried out in Parasitology laboratory in Jimma University. Direct smear was done by senior laboratory technicians and the formol-ether concentration method was done by a laboratory technologist.

Data were entered into a computer and analyzed using SPSS windows version 11.5. Descriptive statistics was used to give a clear picture of background characteristics like age, sex, occupation, history of drug intake and distribution of intestinal parasites. The relationships between proportion of intestinal parasitism and determinant factors for intestinal parasitism such as age and sex were analyzed. Chi-square test was used to see crude association of sex and the proportion of intestinal parasitism. P-value less than 0.05 was considered as statistically significant.

Written permission was obtained from town administrative officials prior to start the study. Verbal consent was obtained from each individual before conducting interview and sample collection. The procedure was non invasive and has no harm to the study subjects. Those who had parasites were given a prescription order so that they could purchase appropriate anti parasitic drugs.

\section{Results}

A total of 239 households were selected for investigation. Of these 31 (12.9\%) were excluded because of inability to provide specimen. For this reason a total of 208 households were included in the study. A total of 940 individuals were selected from these households of which 32 (4.2\%) were excluded due to previous drug intake. As a result, 908 individuals from selected households participated in the study. Majority 754 (83\%) of the subjects were found to have single or multiple intestinal parasitic infections while 154 (17\%) were free of any parasite. Of the entire positive for the parasite, 430 were females and 324 males with female to male ratio of 1:0.8. 
The mean age of the participants who had intestinal parasite was $23 \pm 16$. Slightly less than $50 \%$ were students and the share of adults above 18 years of old was 360 (47.8.0\%).

Table 1: Frequency distribution by sex, age, occupation and drug history of the study subjects for positive parasites ( $n=754)$, Jimma, 2005.

\begin{tabular}{lrr}
\hline $\begin{array}{l}\text { Background } \\
\text { characteristics }\end{array}$ & Frequency & Percentage \\
\hline $\begin{array}{l}\text { Gender } \\
\text { Male }\end{array}$ & 324 & 43.0 \\
$\quad$ Female & 430 & 57.0 \\
Age Group & & \\
$<1$ & 7 & 0.9 \\
$1-4$ & 44 & 5.8 \\
$5-14$ & 215 & 28.5 \\
$15-18$ & 128 & 17.0 \\
$>18$ & 360 & 47.8 \\
Occupation & & \\
Student & 375 & 49.7 \\
Private business & 77 & 10.2 \\
Housewives & 60 & 8.0 \\
Government employee & 56 & 7.4 \\
House maids & 37 & 4.9 \\
Farmers & 28 & 3.7 \\
No specific jobs & 51 & 6.8 \\
Dependent & 53 & 7.0 \\
Others & 17 & 2.3 \\
\hline
\end{tabular}

${ }^{*}$ Elderly, small children

** Not specified

Different types of parasites including protozoans, trematode (flukes), cestodes and nematodes (round worms) were detected from the stool samples of study participants. The prevalence of $T$. trichiura infection was $60.9 \%$ followed by $40.9 \%$ of $A$. lumbricoides. Of these, trichuriasis, ascariasis and schistosomiasis infections emerged as a single parasite in $124(16.4 \%), 44$ (5.8\%), and 11 (1.5\%) individuals, respectively. T. trichiura with A. lumbricoides, hookworms and S. mansoni occurred to share 102 (13.5\%), $33(4.4 \%)$ and 17 (2.3\%) of double infections, respectively. Ascaris and trichuris were commonly found with hookworms and S. mansoni as triple infections. T. trichiura, A. lumbricoides, and hookworms were the most common and Taenia saginata and $S$. stercoralis were the least common reported intestinal parasites among the residents of Jimma town (Table 2). For both sexes, the proportion of infections was higher for helminths compared to protozoa, i.e., about 4.7 times (Table 2, 3).

$H$. nana and $S$. mansoni were found to predominantly affect male population than female population $(\mathrm{P}<0.05$,
Table 3). Active amoebiasis was relatively common in school children whereas E. histolytica was found in 5.6\% among school-children. Hookworm ova and E. histolytica cysts were higher (28.6\%) in children under 1 year of age than in other age groups. Trichuriasis was highly prevalent in all age groups (57\%-75\%). The highest was found in teenagers. Hookworm infections were common in school children and teenagers. Ascariasis, taeniasis, schistosomiasis and S. stercoralis infections (55.5\%, $4.7 \%, 32.0 \%$ and $3.1 \%)$, respectively were most common in teenagers. Significant proportion of teenagers were infected by S.mansoni $(\mathrm{P}<0.05)$ and ascaris.

The rate of infection by H. nana (20.5\%) and G. lamblia cysts and trophozoites (29.5\% and $18.2 \%)$, respectively were higher in preschool children compared to the other age groups (Table $4, \mathrm{P}<0.05$ ).

Regarding the types of intestinal parasites per individual, 1,2 , and 3 types of parasites were identified in 239 (31.7\%), 270 (35.8\%) and 180 (23.8\%) of those infected while 4 and 5 parasitic species were found in 59 (7.8\%) and $6(0.8 \%)$ respectively (Figure 1$)$. Generally, multiple infections (polyparasitism) were seen in 515 (56.7\%) of the total examined and $68.3 \%$ of those with intestinal parasites.

Table 2: Distribution of intestinal parasites among study subjects in Jimma ( $n=908)$, Jimma, 2005.

\begin{tabular}{lrr}
\hline Types of Parasites & Frequency & Percentage \\
\hline Protozoan parasites & & \\
Amoeba cyst & 127 & 14.0 \\
Amoeba trophozoite & 28 & 3.1 \\
$\quad$ Giardia cyst & 93 & 10.3 \\
$\quad$ Giardia trophozoite & 33 & 3.6 \\
Helminths & & \\
Nematodes & & \\
$\quad$ Trichuris trichiura & 553 & 60.9 \\
$\quad$ Ascaris lumbricoides & 371 & 40.9 \\
$\quad$ Hookworms & 159 & 17.5 \\
$\quad$ Strogyloides & & \\
stercoralis & 19 & 2.1 \\
Cestodes & & \\
$\quad$ Hymenolopis nana & 45 & 5.0 \\
$\quad$ Taenia saginata & 21 & 2.3 \\
Tremtodes(flukes) & & \\
$\quad$ Schistosoma & & \\
$\quad$ mansoni & & \\
$\quad$ Others* & 134 & 1.1 \\
* Enterobius vermicularis & & \\
** Multiple infections were found & &
\end{tabular}


Table 3: Distribution of intestinal parasites in relation to sex of residents of Jimma town, Jimma, 2005.

\begin{tabular}{lllll}
\hline Type of Parasites & \multicolumn{2}{l}{ Male $\mathbf{( n = 3 2 4 )}$} & \multicolumn{2}{l}{ Female $\mathbf{( n = 4 3 0 )}$} \\
\cline { 2 - 5 } & No. & Percent & No. & Percent \\
\hline Protozoans & & & & \\
$\quad$ Amoeba cyst & 52 & 16.0 & 75 & 17.4 \\
Amoeba trophozoite & 10 & 3.1 & 18 & 4.2 \\
$\quad$ Giardia cyst & 44 & 13.6 & 49 & 11.4 \\
$\quad$ Giardia trophozoite & 15 & 4.6 & 18 & 4.2 \\
Helminths & & & & \\
A. lumbricoides & 170 & 52.5 & 201 & 46.7 \\
T. trichiura & 243 & 75.0 & 310 & 72.1 \\
Hookworms & 72 & 22.2 & 87 & 20.2 \\
S. stercoralis & 5 & 1.5 & 14 & 3.3 \\
H. nana & 31 & 9.6 & 14 & 3.3 \\
$\quad$ Taenia saginata & 8 & 2.5 & 13 & 3.0 \\
$\quad$ S. mansoni & 74 & 22.8 & 60 & 14.0 \\
$\quad$ Others* & 2 & 0.6 & 8 & 1.9 \\
\hline * Enterobius vermicularis & & & &
\end{tabular}

*Enterobius vermicularis

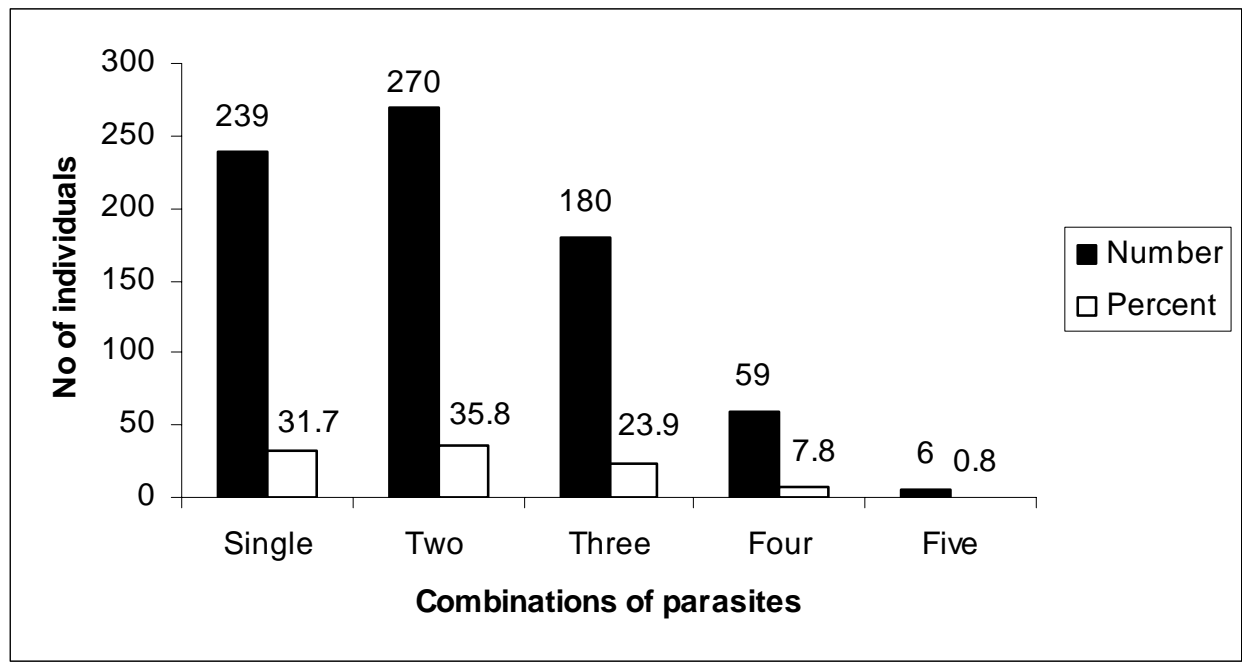

Figure 1: Types of intestinal parasites identified per individual among residents of Jimma town, Jimma, 2005.

Table 4: Distribution of intestinal parasites among different age groups in Jimma town residents, Jimma, 2005.

\begin{tabular}{|c|c|c|c|c|c|}
\hline \multirow[t]{2}{*}{ Types of parasites } & \multicolumn{5}{|c|}{ Age group in years (No) } \\
\hline & $\begin{array}{l}<1 \text { * }(n=7) \\
\text { No }(\%)\end{array}$ & $\begin{array}{l}\text { 1-4 }(n=44) \\
\text { No }(\%)\end{array}$ & $\begin{array}{l}5-14(n=215) \\
\text { No }(\%)\end{array}$ & $\begin{array}{l}15-18(n=128) \\
\text { No }(\%)\end{array}$ & $\begin{array}{l}>18(n=360) \\
\text { No }(\%)\end{array}$ \\
\hline \multicolumn{6}{|l|}{ Protozoans } \\
\hline E. hystolytica cyst & $2(28.6)$ & $8(18.2)$ & $41(19.1)$ & 19(14.8) & $57(15.8)$ \\
\hline $\begin{array}{l}\text { E. hystolytica trophozoite } \\
\text { G. lamblia cyst } \\
\text { G. lamblia trophozoite }\end{array}$ & $\begin{array}{l}0(0.0) \\
2(28.6) \\
1(14.3)\end{array}$ & $\begin{array}{l}0(0.0) \\
13(29.5) \\
8(18.2)\end{array}$ & $\begin{array}{l}12(5.6) \\
25(11.6) \\
7(3.3)\end{array}$ & $\begin{array}{l}3(2.3) \\
16(12.5) \\
3(2.3)\end{array}$ & $\begin{array}{l}13(3.6) \\
37(10.3) \\
14(3.9)\end{array}$ \\
\hline \multicolumn{6}{|l|}{ Helminths } \\
\hline A. lumbricoides & $2(28.6)$ & 14(31.8) & $112(52.1)$ & $71(55.5)$ & $172(47.8)$ \\
\hline T. trichuria & $4(57.1)$ & $32(72.7)$ & $158(73.5)$ & $96(75.0)$ & $263(73.0)$ \\
\hline Hookworms & $2(28.6)$ & $6(13.6)$ & $55(25.6)$ & $32(25.0)$ & $64(17.8)$ \\
\hline S. stercoralis & $0(0.0)$ & $0(0.0)$ & $6(2.8)$ & $4(3.1)$ & $9(2.5)$ \\
\hline H. nana & $1(14.3)$ & $9(20.5)$ & $19(8.8)$ & $9(7.0)$ & $7(1.9)$ \\
\hline Taenia saginata & $0(0.0)$ & $0(0.0)$ & $5(2.3)$ & $6(4.7)$ & $10(2.8)$ \\
\hline S. mansoni & $1(14.3)$ & $6(13.6)$ & $28(13.0)$ & $41(32.0)$ & $58(16.1)$ \\
\hline Others* & $0(0.0)$ & $0(0.0)$ & $2(0.9)$ & $2(1.6)$ & $6(1.7)$ \\
\hline
\end{tabular}

$<1$ year but above 4 months $=$ Infants, $=1-4$ years $=$ Preschool children,

$5-14$ years $=$ School children, $15-18$ years $=$ teenagers, $>18$ years $=$ Adults;

* Enterbius vermicularis; multiple (more than 1) parasitic infections present 


\section{Discussion}

Of 908 residents, 754 (83.0\%) were infected with one or more intestinal parasites. Despite of higher coverage of latrine, this finding shows a significantly higher infection rate. This is because of poor water supply, which is below the standard. According to Planning and Economic Development for Oromyia (19), a quarter (25\%) of the population utilized water from sources other than pipes. Poverty may also contribute to the high parasite prevalence (19). Poor environmental sanitation and climatic conditions (hot, wet and humid) favor the persistence of parasite ova in the soil. This finding is consistent with a study done by Yeneneh (9) where a prevalence of $82.7 \%$ intestinal parasitosis found in residents of 4 villages in southwestern Ethiopia. Another study conducted by Legesse and Erko among school-children around Lake Langano reported a prevalence of $83.8 \%$ (20). This result was higher than another school-based study conducted in Jimma by Haile et al (10) who reported a prevalence of $68.4 \%$. The prevalence in our study was also higher compared to other community-based studies conducted in Saudi Arabia by Al-Shammari et al (21) showing an overall prevalence of $32.2 \%$. This variation could be owing to environmental hygiene differences, economic, educational status of the study subjects and climatic conditions.

In this study, multiple infections (polyparasitism) occured in 515 individuals making $56.7 \%$ of the total examined subjects and $68.3 \%$ of those who had intestinal parasites. This is similar to a study done in Argentina portraying a polyparasitism of $61.6 \%$ among marginally poor people (22). Double infection was frequently seen in more than a third (35.8\%) of the study subjects. The prevalence of multiple infections was higher compared to the previous studies (8-12). Sample size determination, study population and the methods used could attribute to this observed difference in detections of various parasites.

The prevalence of amoebiasis and giardiasis in this study was $3.1 \%$ and $3.6 \%$, respectively. These are within the range of the nation-wide prevalence rate for amoebiasis and giardiasis $(5,14)$. The prevalence of giardiasis is nearly similar to that of Birrie and Erko report of 3.1\% among non-school children (23). Three hundred seventy one (41.0\%) of the study subjects were infected with $A$. lumbricoides and the rate falls just above the upper range for nation wide prevalence rate of ascariasis (which is from 30-40) (13).

The average prevalence of ascaris in most other African countries is reported to be $32 \%$, ranging from $16 \%$ to $48 \%$ (3). Trichuris trichiura was found in 553(61\%) of the study subjects. The rate was relatively higher compared to the previous studies (8-11).
The prevalence of hookworm infections in this study was $159(17.5 \%)$. The rate is higher to the findings of previous school-based study by Haile et al (10) which was $0.3 \%$. The present findings on prevalences of $\mathrm{S}$. stercoralis, $H$. nana, and $T$. saginata were similar to the findings of previous studies reported by Tesfamichael, Kloos et al., McConnel and Armstrong, Woldemichael et al $(5,12,14,15)$.

The overall prevalence rate of schistosomiasis was $14.8 \%$. This result could be considered high taking into account the availability of municipal water system in such a big town like Jimma. However, all persons do not use this source. A quarter of people in the study area use other sources. The presence of insufficient water supply may have forced the people to use other water sources such as the rivers crossing the town.. Reports of various studies revealed that prevalence of schistosomiasis was from $4 \%-29 \%$ around villages near Lake Abaya and Gorgora in north coast of Lake Tana $(15,24)$, respectively. In these studies, infection rates were higher in communities reside near to the river banks.

H. nana and S. mansoni seriously affected males than females and the association was statistically significant $(\mathrm{P}<0.01$ and $\mathrm{P}<0.05)$, respectively. Moreover, $A$. lumbricoides and $S$. mansoni infections were common in teenagers than in the other age groups $(p<0.05)$ in both cases. The reason for the association is not clear but as to schistosomiasis, males may have higher exposure to river water than females. Giardiasis and $H$. nana infections were common in pre school children compared to the other age groups. The association was statistically significant in all cases $(p<0.05)$. The reasons of higher infection rate for that of the study done on pre school-children could be due to modes of transmission. Giardiasis is transmitted through contaminated hands, food etc whereas $H$. nana is by fecal-oral means. Thus, children can be the first vulnerable group to be contaminated.

In this study, protozoan infections were in general higher in children especially in those under 5 years of age while there was reduction as age increased. The reason could be due to slow development of immunity in adults to the protozoan parasites and better awareness in washing hands and other personal hygiene measures. On the other hand, there was no significant difference in the rate of infection due to helminths in relation to age. This is because of different evasion mechanisms to immunity by helminths.

In conclusion, intestinal parasitosis in Jimma town is very high. The proportion of infections was higher for helminthes compared to protozoa. The high prevalence of parasitosis in the study area indicated that much work remains to be done to improve the health of the

Ethiop.J.Health Dev. 2007;21(1) 
people. Measures including education on personal and environmental hygiene should be taken into account to reduce the prevalence.

\section{Acknowledgements}

We would like to thank the Office of Planning and Economic Development of Jimma Zone, Jimma town municipality and the respective Kebele administrations for providing us the necessary information and helped us during sample collections. Jimma University is acknowledged for financing the study. We are grateful to the data collectors and others who cooperated with us during the study.

\section{References}

1. World Health Organization. Control of tropical diseases. 1998; WHO, Geneva.

2. Evans AC, Stephenson LS. Not by drugs alone: the fight against parasitic helminths. World Health Forum 1995;16:258-261 ( Medline).

3. WHO Technical Report Series 749. Prevention and control of intestinal parasitic infections. WHO, Geneva, 1987.

4. WHO. Report on the WHO informal consultation on the use of chemotherapy for the control of morbidity due to soil-transmitted nematodes in humans. Division of the control of tropical diseases, WHO, Geneva, 1996.

5. Tesfa-Yohannes T.M, Kloos H. Intestinal parasitism. In: Zein A.Z and Helmut Kloos (Eds). The ecology of health and disease in Ethiopia, Ministry of Health, Addis Ababa, 1988; 214-230.

6. Kumie A, Ali A. An overview of environmental health status in Ethiopia with particular emphasis to its organization, drinking water and sanitation: a literature survey. Ethiop J Health Dev. 2005;19 (2):89-103.

7. $\mathrm{MOH}$ of Ethiopia. Comprehensive health service directory. 1991, MOH, Addis Ababa, Ethiopia.

8. Jemaneh L. Comparative prevalence of some common intestinal helminthic infections in different altitudinal regions in Ethiopia. Ethiop Med J.1998;36:1-8.

9. Yeneneh H. Survey of intestinal parasites in Bure area, Illubabor, southwest Ethiopia. Ethiop J Health Dev. 1994;8:29-35.

10. Haile G, Jirra $C$, Mola $T$. Intestinal parasitism among Jiren elementary and junior secondary school students, southwest Ethiopia. Ethiop J Health Dev. 1994;8:37-41.
11. Lo CT, Ayele T, Hailu Birre H. Helminths and snail survey in Harerge region of Ethiopia with special reference to shistosomiasis. Ethiop Med J. 1989;7583.

12. Kloos $\mathrm{H}$, Lemma $\mathrm{H}$, Kirub $\mathrm{B}$, et al. Intestinal parasitism in migrant farm labourer populations in irrigation schemes in the Awash Valley, Ethiopia, and in major labour source areas. Ethiop Med J. 1980;18:53-62.

13. Tedla S, Ayele T. Ascariasis distribution in Ethiopia. Ethiop. Med. J. 1986; 24:79-86.

14. McConnel E, Armstrong JC. Intestinal parasitism in fifty communities on the central plateau of Ethiopia. Ethiop Med J. 1976;14:159-168.

15. Wodemichael T, Endeshaw T, Shibre T, Gebre T, Haddis $M$, Tilahun $D$, et al. Intestinal parasitic infections in western Abaya with special reference to Shistosoma mansoni. Ethiop J Health Dev. 1999;13:25-26.

16. Lo CT, Kloos H, Birre H. Schistosomiasis. In: Ahmed Z \& Kloos H (eds.), The Ecology of health and disease in Ethiopia. MOH, Addis Ababa, 1988:196-213.

17. Federal Democratic Republic of Ethiopia, Central Statistical Authority of Ethiopia. The 1994 E.C (2001/2002) population and housing census of Ethiopia, Statistical Abstracts, 2003, Addis Ababa, Ethiopia

18. Ministry of Planning and Economic Development. Report on the household food security study of four towns, Addis Ababa, Ethiopia. Feb. 1994.

19. Bureau of Planning and Economic Development for Oromyia. Office of Planning and Economic Development for Jimma Zone. Socio-economic profile of Jimma woredas. Sep. 1991; Jimma, Ethiopia.

20. Legesse M, Erko B. Prevalence of intestinal parasites among school children in a rural area close to the southeast of lake Langano, Ethiopia. Ethiop J Health Dev. 2004;18:116-120.

21. Al-Shammari S, Khoja T, El-Khwasky F, Gad A. Intestinal parasitic diseases in Riyadh, Saudi Arabia: prevalence, socio-demographic and environmental associates. Trop Med Int Health. 2001;6:184-189.

22. Gamboa MI, Basualdo JA, Kosubsky L, Costas E, Cueto Rua E, Lahitte HB. Prevalence of intestinal parasitosis within three population groups in $\mathrm{La}$ Plata, Argentina. Eur J Epidemiol. 1998;14:55-61.

23. Birrie H, Erko B. Giardiasis in Ethiopia. Ethiop. J. Health Dev. 1995;9(2):77-80

24. Dagnew M. Status of Schistosoma mansoni infection at Gorgora, northwest Ethiopia. Ethiop J Health Dev. 1999;13:15-19. 